\title{
Proliferative activity of normal and neoplastic urothelium and its relation to epidermal growth factor and transferrin receptors
}

\author{
C Limas, R Bair, P Bernhart, P Reddy
}

\begin{abstract}
Aims-To investigate the proliferative activity (given by the Ki67 index) of the normal, atypical, and neoplastic urothelium and its relation to the cellular reactivity for the epidermal growth factor (EGFr) and transferrin (Tfr) receptors. Methods-The Ki67 index and the level of EGFr and Tfr reactivity were determined on frozen sections from 82 patients with urothelial cancer. Relevant clinical material was reviewed to establish correlations with the degree of atypia and invasion.

Results-Morphologically normal urothelium, whether derived from controls or patients with cancer, exhibited a low Ki67 index (less than $0.1 \%$ ) and weak receptor reactivity. In transitional cell carcinomas (TCCs) the Ki67 index was increased: it ranged between $0.7 \%$ and $10 \%$ in non-invasive and exceeded $10 \%$ in $88 \%$ of the invasive TCCs. Strong positive reactions for EGFr were seen only in invasive TCCs, but in $47 \%$ of invasive TCCs the EGFr was not "overexpressed" and did not match the Ki67 index. A better correlation was found between the Ki67 index and the Tfr which was positive in $26 \%$ of the non-invasive and in $71 \%$ of the invasive tumours. All three variables were increased in severe atypia but varied considerably in lesser degrees of atypia.
\end{abstract}

Conclusions-Despite the absence of a close correlation, accelerated growth and enhanced receptor expression were characteristic of invasive cancers. These results suggest that the growth rate in TCCs is not causally related to overexpression of growth factor receptors but that the latter is an abnormality which may accompany the malignant phenotype.

Department of Urologic Surgery, VA Medical Center and University of Minnesota,

Minneapolis, USA

C Limas

R Bair

P Bernhar

P Reddy

Correspondence to: Dr Catherine Limas, Department of Pathology, Veterans Affairs Medical Center, One Veterans Drive, Minneapolis, MN 5541 USA.

Accepted for publication 7 April 1993
Neoplasia is characterised by unregulated cell proliferation and differentiation which, at some point, involves the interaction of growth stimuli with specific cellular receptors. The possibility of an inappropriate overexpression of growth related receptors in tumour cells has been evaluated in several types of neoplasms and, specifically, in the case of urothelial cancer, an abnormal increase in the receptors for the epidermal growth factor has repeatedly been reported. ${ }^{1-4}$ The clinical relevance of this observation for the initiation or maintenance of accelerated cell proliferation, however, remains speculative.

In this study we attempted to examine the relation between proliferative state and reactivity for two growth related receptors in normal, atypical, and neoplastic urothelium. As a measure of proliferative activity we used the expression of the nuclear antigen Ki67, expressed in cells in mitosis but not in $\mathrm{G}_{\mathrm{o}}$ phase. ${ }^{56}$ Of the growth related receptors, we chose to study those for the epidermal growth factor (EGFr) and transferrin (Tfr) which are biochemically and physiologically distinct, can be expressed independently, and have been demonstrated in urothelial cells. Many published data support the relevance of these receptors to cell growth. ${ }^{7-10}$ In particular, the EGFr seems to be enhanced when examined immunohistochemically, ${ }^{13}$ by ligand binding, ${ }^{2}$ and mRNA expression ${ }^{4}$ in certain tumours of the human urinary bladder. The immunohistochemical detection of the $\mathrm{Tfr}$ in bladder tumours has already been shown to correlate with the probability of recurrence. ${ }^{11}$ We addressed the question of whether the cellular reactivity for these receptors correlates with the proliferative state of the tumours and is, therefore, a measure of their growth potential.

\section{Methods}

Tissue specimens were derived from men with an average age of 64 years and were classified into the following four categories (table 1): (1) control normal urothelium from 17 subjects without urothelial neoplasia; (2) morphologically normal urothelium from 14 patients with urothelial neoplasia diagnosed in another biopsy specimen; (3) urothelium

\begin{tabular}{lll} 
Table 1 & Distribution of tissue specimens in four categories & \\
\hline Category & Material & Number of cases \\
\hline 1 & Control normal urothelium & 17 \\
2 & Normal urothelium from patients with urothelial neoplasia & 14 \\
3 & Urothelial atypias-CIS & 15 \\
4 & Urothelial neoplasms & 86 \\
\end{tabular}


with morphological atypia, ranging from moderate to severe, and carcinoma in situ (CIS). Eight of the 15 patients in this category had synchronous or metachronous invasive bladder cancers; (4) primary urothelial tumours originating either in the bladder (32 cases) or the renal pelvis (4 cases).

The specimens were obtained by biopsy or surgical resection, frozen immediately, and stored at $-70^{\circ} \mathrm{C}$. The clinical histories as well as all cytological and pathological material were reviewed and each case was assigned one of the four categories. The tumours in category 4 were subclassified into 17 with muscle invasion (T2 or higher) demonstrable in at least one biopsy or the surgical specimen, 16 non-invasive ( $\mathrm{Ta}$ ), and three with superficial subepithelial invasion (T1). A minimum two year follow up was done.

None of the patients in category 1 had any evidence of urothelial neoplasia while all those in category 2 had at least one diagnosis of transitional cell carcinoma (TCC documented by biopsy). Only biopsy specimens with intact, morphologically benign epithelium, without inflammation or metaplastic changes, were included in categories 1 and 2 . Cases were classified in category 3 by applying well established morphological criteria. ${ }^{12} 13$ Staging and grading of these tumours were performed according to established guidelines. All muscle invasive TCCs were grade 3 or higher. The remaining tumours consisted of an inverted papilloma, three grade 1,10 grade 2 , and five grade $2 / 3$ TCCs.

An average of three tissue blocks (range 1-5) were examined from each patient. Multiple (14-26) serial sections were cut at 6 $\mu \mathrm{m}$, the first and last sections were stained with haematoxylin and eosin and the remaining intervening sections were used for the various immunoperoxidase studies. Each assay was performed on duplicate sections and included negative and positive controls. Negative controls consisted of sections incubated in the absence of primary antibody, and positive controls of normal tissues with known reactivity for each of the antigens.

Optimal conditions were determined in preliminary experiments and those yielding consistently reproducible results on a semiquantitative scale were chosen for each antibody. Specimens were considered to be negative if they showed no or only rare foci (less than $10 \%$ ) of weak staining. Specimens with strong staining of over $30 \%$ of the cells were classified as positive. Pale, diffuse or patchy staining in more than $10 \%$ but less than $30 \%$ of the area, together, were classified as weak.

The monoclonal anti-EGF receptor (EGFr) antibody, purchased from Amersham (Arlington Heights, Illinois), has been well characterised, ${ }^{14}$ and the method for its immunohistochemical application has been reported in detail. ${ }^{3}$ The monoclonal antibody directed against $\mathrm{Tfr}$, obtained from BectonDickinson (Mountainview, California), has also been characterised and reported to react with proliferating cells of many histological types. ${ }^{8}$ This antibody was used on acetone fixed frozen sections at 1 in 4 and 1 in 10 dilutions: all other conditions were the same as for the anti-EGFr. The anti-Ki67 antibody ${ }^{15}$ (Dakopatts, Denmark) was applied on acetone fixed frozen sections at a 1 in 33 dilution. The incidence of $\mathrm{Ki}-67$ positive nuclei was calculated as follows: a disk with a $1 \mathrm{~cm}^{2}$ grid divided into 100 equal squares was inserted into the eyepiece and the number of labelled as well as the total number of nuclei were counted using the $\times 40$ objective. All available fields were scanned. The variability in the incidence of positive nuclei was evaluated and the fields for quantitation were selected to give a fair representation of the entire normal (or neoplastic) cell population. At least 500 (usually 2000-3000) nuclei were counted in each section. Finally, the average percentage of positive nuclei for each case was calculated and is referred to as the $\mathrm{Ki}-67$ index. The same grid was used to facilitate the semiquantitative assessment of the staining for the receptors.

Statistical analysis was performed using Wilcoxon's and Spearman's rank tests as well as the $\chi^{2}$ test, as indicated.

\section{Results}

CATEGORY 1

In 11 of the $17(65 \%)$ normal control cases the $\mathrm{Ki}-67$ index was less than $0 \cdot 1 \%$ and in only one case did it exceed $2 \%$ (fig $1 \mathrm{~A}$ ). Excluding this case (index of $3.6 \%$ ), the average percentage of positive nuclei was $0.08 \%$, but their distribution along the mucosa varied because of their tendency to segregate in some fields and to be more common in the deeper layers.

Figure 1A also shows the reactivity for the receptors in these cases. Eleven of the 17 control mucosa tissue specimens gave identical reactions for both receptors (65\% concordance), five (29\%) showed more extensive staining for transferrin, and one (6\%) for EGFr. The reactivity for both receptors was localised to the deeper layer with only a few exceptions, and, in general, more layers reacted with the anti-Tfr than the anti-EGFr.

\section{CATEGORY 2}

In this category the frequency and distribution of $\mathrm{Ki}-67$ positive nuclei were similar to those observed in category 1 . The $\mathrm{Ki}-67$ index was less than $0.1 \%$ in eight of the 14 $(57 \%)$ cases and between $0.1 \%$ and $2 \%$ in the remaining six (43\%) (fig $1 \mathrm{~B}$ ). In most cases the reactions for EGF and transferrin receptors were weakly positive and limited to the deeper layers as in the mucosal tissue samples derived from patients without urothelial neoplasms. The level of reactivity was the same for the two receptors in four cases $(28 \%)$. In seven $(50 \%)$ cases, the transferrin receptor reactions were more extensive, and in three $(23 \%)$, these were weaker than those of the anti-EGFr. The differences between categories 1 and 2 were insignificant. 

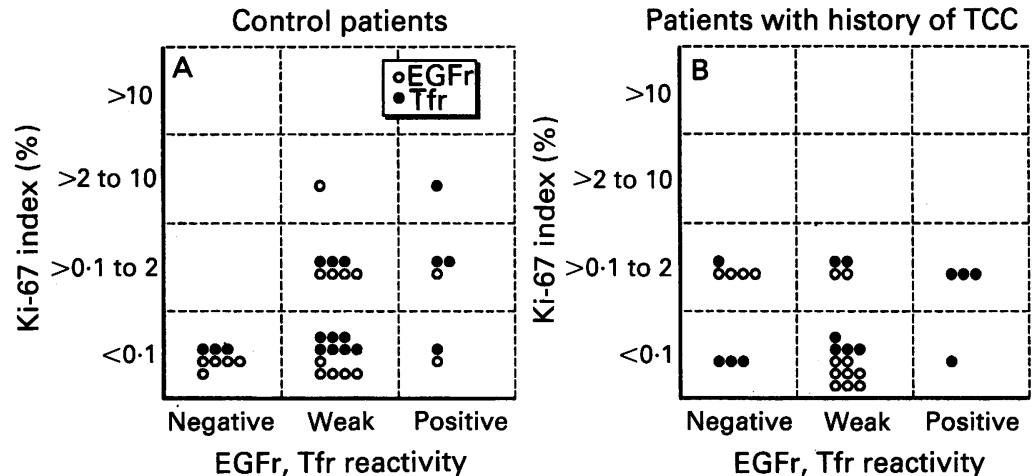

Figure 1 Distribution of cases of morphologically normal urothelium according to Ki-67 index and reactivity for EGFr, Tfr: (A) Control subjects; $(B)$ patients with urothelial neoplasia elsewhere. Each case is represented by an open (EGFr) or closed (Tfr) circle.

The combined results for categories 1 and 2 are shown in tables 2 and 3 . Of the 25 specimens with morphologically normal urothelium, $19(61 \%)$ had a $\mathrm{Ki}-67$ index of less than $0.1 \%, 11(36 \%)$ between $0.1 \%$ and $2 \cdot 0 \%$, and one (3\%) over $2 \cdot 0 \%$. EGFr expression was absent in $29 \%$, weakly positive in $64.5 \%$, and positive in $6.5 \%$. The transferrin receptor was negative in $22.5 \%$, weakly positive in $52 \%$, and positive in $25 \cdot 5 \%$. Concordance of EGF and Tfr reactivity was found in $48 \%$ of the cases. The anti$\mathrm{T}$ fr reaction was stronger in $36 \%$ and that of the anti-EGFr in $16 \%$ of the cases. Transferrin reactivity seemed to be greater in cases with higher Ki-67 (Spearman's rank correlation $r_{s}=0.560$ ) but no such correlation was noted for the EGFr.

\section{CATEGORY 3}

On the basis of morphological characteristics, six cases were classified as severe atypia-carcinoma in situ (CIS) and nine as moderate atypia. Figure 2 summarises the results of the $\mathrm{Ki}-67, \mathrm{EGFr}$, and $\mathrm{Tfr}$ reactions in this category. The $\mathrm{Ki}-67$ index was over $2 \cdot 0 \%$ in all

Table 2 Correlation of Ki-67 indices with histological findings

\begin{tabular}{|c|c|c|c|c|}
\hline \multirow[b]{2}{*}{ Histology } & \multicolumn{4}{|c|}{ Ki-67 index (\%) } \\
\hline & $<0.1$ & $>0.1$ to 2 & $>2$ to 10 & $>10$ \\
\hline $\begin{array}{l}\text { Normal* } \\
\text { Moderate atypia } \\
\text { Severe atypia-CIS } \\
\text { All Neoplasms } \\
\text { Non-invasive and minimally invasive } \\
\text { papillary TCCs }\end{array}$ & $\begin{array}{r}61 \\
44 \\
0 \\
0 \\
0\end{array}$ & $\begin{array}{r}36 \\
0 \\
0 \\
20 \\
37\end{array}$ & $\begin{array}{r}3 \\
56 \\
17 \\
33 \\
52\end{array}$ & $\begin{array}{c}0 \\
0 \\
83 \\
47 \\
11 \dagger\end{array}$ \\
\hline TC̆Cs with muscle invasion & 0 & 0 & 12 & 88 \\
\hline
\end{tabular}

*Includes categories 1 and 2

†Two grade 2-3 TCCs without muscle invasion but with penetration of the basal lamina TCC: Transitional cell carcinoma

Table 3 Correlation of EGFr and Tfr reactivity with conventional histology

\begin{tabular}{|c|c|c|c|c|c|c|}
\hline \multirow[b]{2}{*}{ Histology } & \multicolumn{3}{|l|}{$E G F r$} & \multicolumn{3}{|l|}{$T f r$} \\
\hline & Negative & Weak & Positive & Negative & Weak & Positive \\
\hline $\begin{array}{l}\text { Normal` } \\
\text { Moderate atypia } \\
\text { Severe atypia-CIS } \\
\text { All neoplasms } \\
\text { Non-invasive and minimally } \\
\text { invasive papillary TCCs }\end{array}$ & $\begin{array}{r}29 \\
11 \\
0 \\
19 \\
32\end{array}$ & $\begin{array}{l}64 \cdot 5 \\
78 \\
34 \\
56 \\
68\end{array}$ & $\begin{array}{l}6 \cdot 5 \\
11 \\
66 \\
25 \\
0\end{array}$ & $\begin{array}{c}22 \cdot 5 \\
11 \\
0 \\
0 \\
0\end{array}$ & $\begin{array}{r}52 \\
56 \\
0 \\
53 \\
74\end{array}$ & $\begin{array}{c}25 \cdot 5 \\
33 \\
100 \\
47 \\
26\end{array}$ \\
\hline TCCs with muscle invasion & 6 & 41 & 53 & 0 & 29 & 71 \\
\hline
\end{tabular}

*Includes categories 1 and 2

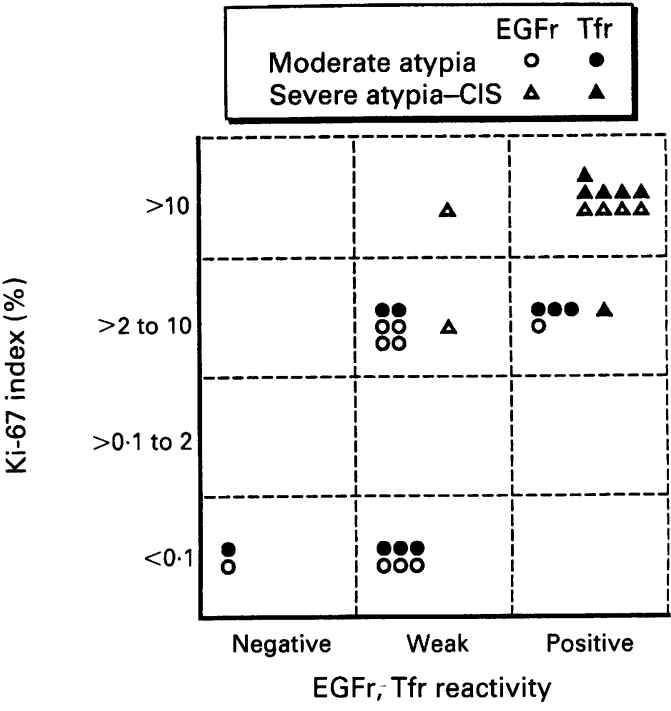

Figure 2 Distribution of cases with atypia-CIS according to the Ki-67 index and reactivity for EGFr, Tfr.

six cases with severe atypia-CIS and over $10.0 \%$ in five $(83 \%)$ of these. Of the nine cases with moderate atypia, four (44\%) had a very low (less than $0 \cdot 1 \%$ ) $\mathrm{Ki}-67$ index while the other five (56\%) fell in the $2 \cdot 0-10.0 \%$ range (fig 2, table 2). All six cases of severe atypia-CIS were strongly positive for the transferrin receptor and four $(66 \%)$ of these were also strongly positive for the EGF in all atypical cells (fig $3 \mathrm{~A}$ and $3 \mathrm{~B}$ ). The cases of moderate atypia showed a spectrum of reactivity for the two receptors (fig 2, table 3 ).

\section{CATEGORY 4}

All urothelial neoplasms had a $\mathrm{Ki}-67$ index above $0 \cdot 1 \%$. The range was between $0.7 \%$ and $32 \%$, with a significant difference in growths with no or minimal invasion (Ta, $\mathrm{T} 1$ ) and those with muscle invasion (T2 or higher) $(p<0.01)$ (table 2$)$. Three grade $2 / 3$ transitional cell carcinomas with only superficial invasion ( $\mathrm{T} 1$ ) had $\mathrm{Ki}-67$ indices ranging from $2 \cdot 0 \%$ to $15 \cdot 0 \%$. The $\mathrm{Ki}-67$ index had a good correlation with invasion: muscle invasion was not seen in any of the tumours with an index of less than $2.0 \%$ but it was noted in $17 \%$ of those with an index between $2.0 \%$ and $10 \%$, and in $88 \%$ of those with an index above $10.0 \%(p<0.01)$. The limited number of cases and the noticeable preponderance of grade 3 among invasive TCCs did not permit a meaningful statistical analysis of the correlation between grade and Ki67 index, independently of the presence of invasion.

$\mathrm{Ki}-67$ positive nuclei were found throughout but unevenly distributed. Their incidence was greater in the cell layers closer to the basement membranes so that they segregated in the deeper strata of the papillary growths and in the periphery of invasive tumour islands (fig 4).

EGFr was detectable in $81 \%$ of urothelial neoplasms while the transferrin receptor was detectable in all (fig 6, table 3). There was a significant difference in the expression of the two receptors between papillary TCCs 


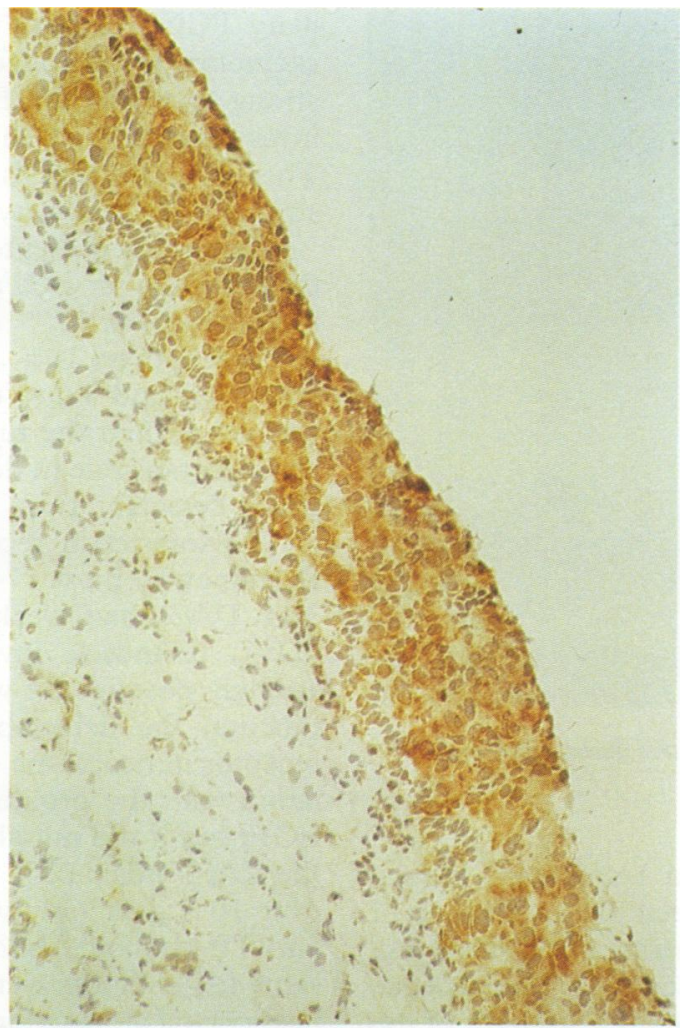

(A)

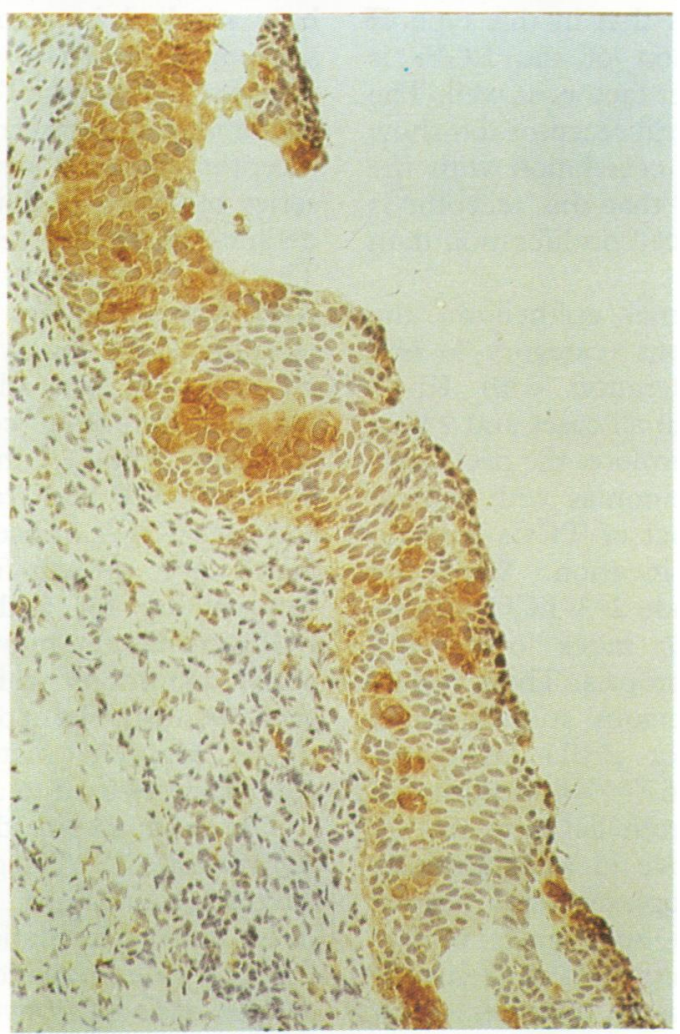

Figure 3 (A) Positive reaction with anti-EGFr in a case of CIS of the urinary bladder. (B) Positive reaction for EGFr sharply confined to patchy areas corresponding to the highly atypical cells.

without muscle invasion and those infiltrating the muscular layers $(p<0.01)$. Only the latter gave strong positive reactions with the anti-EGFr antibody, but these represented only $53 \%$ (nine of 17 ) of the muscle invading tumours. The anti-Tfr antibody gave strong positive reactions with $71 \%$ (12 of 17 ) of the stage T2 or higher tumours and $26 \%$ (five of 19) of low stage TCCs (figs 5,6 , table 3 ).

The correlation of the $\mathrm{Ki}-67$ index with the level of reactivity of the two receptors is shown in fig 6. A high proportion of tumours with large numbers of proliferating cells did not appear to overexpress EGFr. The tumour reactions with the anti-Tfr antibody seemed to correlate with the index of proliferation of the tumour cells (Spearman's rank correlation $\left.\mathrm{r}_{\mathrm{s}}=0.7, \mathrm{p}<0.05\right)$.

Concordant EGF and transferrin receptor reactivity was found in $67 \%$ (24 of 36 ) of the neoplasms. In the remaining 12 cases the $\mathrm{Tfr}$ reactions were stronger than those of the antiEGFr.

In this series only three cases had documented lymph node metastases and these also had muscle invasion, a Ki67 index over $10 \%$, and positive $\mathrm{Tfr}$ activity. Two of these cases were EGFr positive.

\section{Discussion}

The two receptors EGFr and Tfr were selected because they are usually expressed in proliferating cells ${ }^{79}$ and have already been detected in human urothelium. ${ }^{-41116}$ The immunohistochemical approach was chosen because it provides direct visualisation of the intensity, extent, and exact localisation of the reactions on specific cells. The use of serial tissue sections also permits evaluation of all three variables, thus facilitating the interpretation of the correlations between them.

The proliferating cell fraction of the morphologically normal urothelium, as reflected in the $\mathrm{Ki}-67$ index, is very small. In most normal mucosa only one in about 2000 cells is mitotic. This suggests a very low turnover and concurs with previous observations. ${ }^{17} 18$ Interestingly, the $\mathrm{Ki}-67$ indices of the normal looking urothelium from control patients were similar to those from patients with urothelial neoplasms. This may be interpreted as evidence that urothelial neoplasia is a localised, albeit multifocal, process and can exist in the midst of a very stable epithelium. It must be emphasised that only well preserved, non-inflamed, and non-metaplastic urothelium was classified as normal in categories 1 and 2 .

In most normal mucosae the EGF and transferrin receptors were weakly detectable and both seemed to be more strongly expressed in the deeper layers. Because the antibodies used in this study reacted with both occupied and unoccupied receptors, the tissue reactivity was probably unaffected by the presence or absence of ligands. Cells exposed to high ligand concentrations for extended periods of time, however, may downregulate the corresponding receptor and this may explain the apparent absence or weak expression of the EGF receptor from urothelial cells which are exposed to urinary EGF. Alternatively, the reduced detectability of the receptor in the superficial cells could be intrinsic to the differentiation process. Indeed, other stratified epithelia-for 


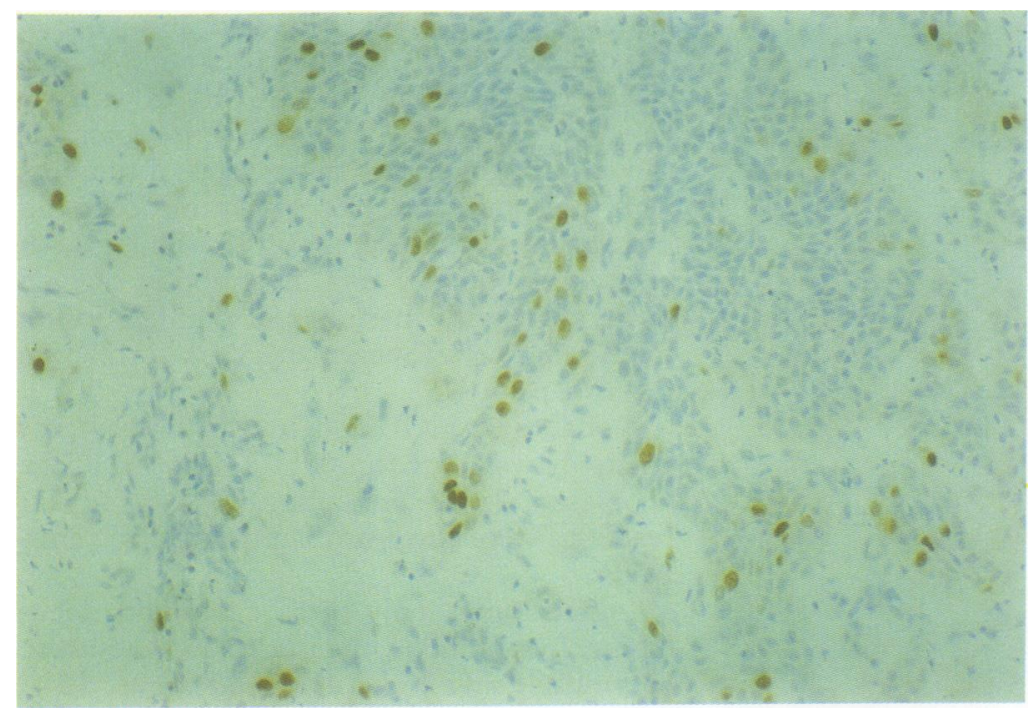

Figure 4 TCC with muscle invasion shows several Ki-67 positive nuclei which are frequently located towards the periphery of tumour islands.

example, squamous and respiratory, clearly show a correlation between the localisation of these receptors and the strata of proliferating, not fully differentiated, cells. ${ }^{310}$ The absence of any correlation between the strength of the EGFr reactions and the $\mathrm{Ki}-67$ index in normal urothelium suggests that in this type of epithelium the expression of the EGFr is under the control of other factors as well. The reactions for the transferrin receptor did show a positive, albeit weak, correlation with the $\mathrm{Ki}-67$ index, suggesting that this receptor is more directly related to cell proliferation than the EGFr.

Compared with normal epithelium, the neoplastic cell populations (category 4) had clearly increased proliferation with $\mathrm{Ki}-67$ indices exceeding $0 \cdot 1 \%$ in all cases and $2 \%$ in $80 \%$ of the cases. Furthermore, the proliferating fraction of the carcinomas with muscle invasion far exceeded that of TCCs with no or only subepithelial invasion. With the exception of two T1, grade 2-3 TCC, all carcinomas with a $\mathrm{Ki}-67$ index over $10 \%$ invaded the muscularis propria. These results agree with those of previous studies which used $(3 \mathrm{H})$ thymidine or BrdU incorporation $^{17} 18$ as well as $\mathrm{Ki}-67^{19-21}$ as indices of proliferative activity in urothelial tumours.

The EGFr was positive in a significantly higher proportion of neoplasms than normal mucosa $(25 \% v 6.5 \%)$ and, more importantly, strong EGFr reactivity was seen only in carcinomas with muscle invasion. Such invasion, however, was accompanied by strong EGFr expression in only $53 \%$ of cases. Therefore, if a tumour is EGFr positive, muscle invasion can be predicted with a high level of confidence, but lack of reactivity for this receptor does not preclude infiltration of the muscularis propria.

The expression of EGFr in non-invasive TCCs was not significantly increased compared with normal. Changes in the detectability of the EGFr seem to occur relatively late in the evolution of papillary urothelial tumours. In contrast to the non-invasive pap- illary TCCs, cases of severe atypia and "flat" cacinoma in situ had a high incidence of strong reactions for EGFr, despite the noninvasive nature of these urothelial changes. Therefore invasion is not a prerequisite for strong EGFr reactivity.

The results presented in fig 6 indicate that the reactions for EGFr do not reflect the proliferation index $(47 \%$ of the TCCs with a $\mathrm{Ki}$ 67 index over $10 \%$ had only weak EGFr reactivity) and led to the conclusion that factors other than the tumour growth rate have an important role in determining the extent of EGFr detectability.

The transferrin receptor was expressed in all tumours; most (74\%) of low stage (Ta, T1) TCCs had weak reactivity while most (71\%) of muscle invasive carcinomas were strongly positive. As was the case for normal mucosa, the detectability of the transferrin receptor in neoplastic cells had a closer correlation with the proliferation indices than the EGFr but it did not always match the level of the $\mathrm{Ki}-67$ index: $25 \%$ of tumours with indices over $10 \%$ gave only weak reactions with the anti-Tfr antibody. Although sections from the same tissue blocks were used for all immunohistochemical reactions, some variability in the preservation of the three antigens might have resulted in a more consistent demonstration of the Ki-67 antigen compared with the two receptors. Tumours which showed discrepancies between EGF and transferrin receptor reactions were re-examined using a series of antibody dilutions and the preponderance of the Tfr reactivity was confirmed. The poor correlation of the EGFr with the $\mathrm{Ki}-67$ index supports the conclusion that this receptor is not simply a marker of proliferating cells and that additional conditions are required to obtain cells with strong EGFr reactivity. The fact that all tumours positive for both EGF and transferrin receptors also had high $\mathrm{Ki}-67$ indices (over 10\%) indicates that a large growth fraction is the common denominator for both receptors. Enhanced EGFr expression, however, may require additional conditions which are more likely to occur in unstable neoplastic cell populations where multiple metabolic and structural abnormalities tend to accrue.

The findings in the cases of urothelial atypia and CIS (category 3) are particularly interesting and need to be extended to a larger number of patients with longer follow up. The cases classified as severe atypia-CIS on the basis of conventional morphological criteria were similar to carcinomas with muscle invasion in terms of the three variables studied. This is consistent with the high incidence of malignant behaviour in urothelial atypia. ${ }^{22}$ The six cases in our series have had persistent cytological atypia (13 to 30 months of follow up) and two were found to have invasive carcinomas elsewhere in the urinary tract. The diversity in receptor expression and cell proliferation rate in cases of moderate atypia suggests that this group includes lesions with variable biological potential. Longer follow up is needed to evaluate the 


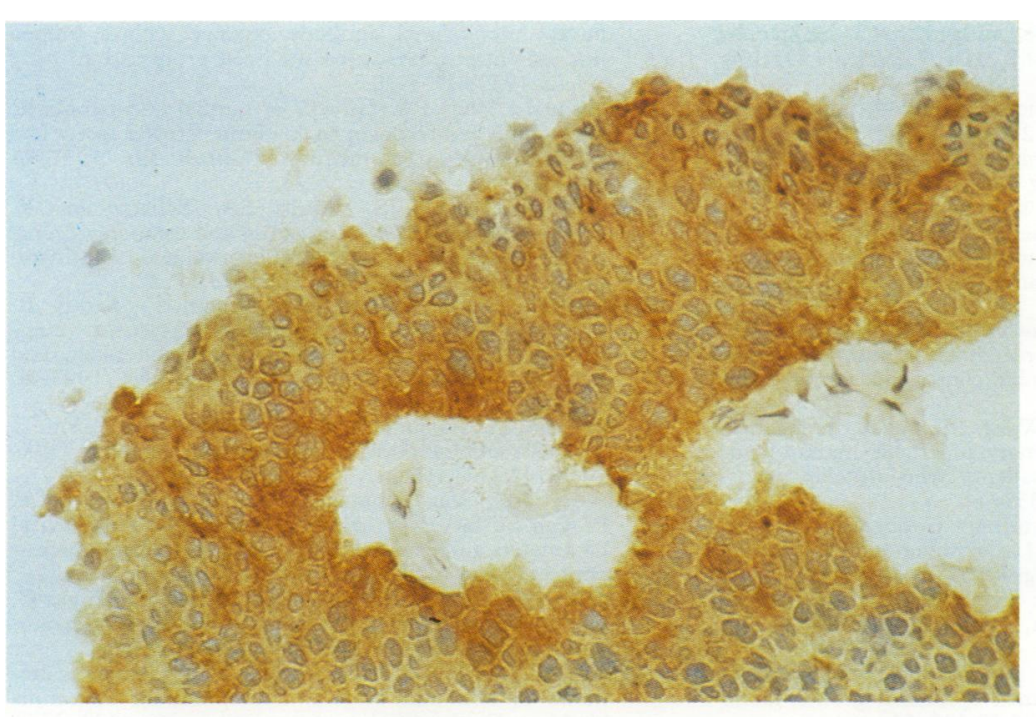

(A)

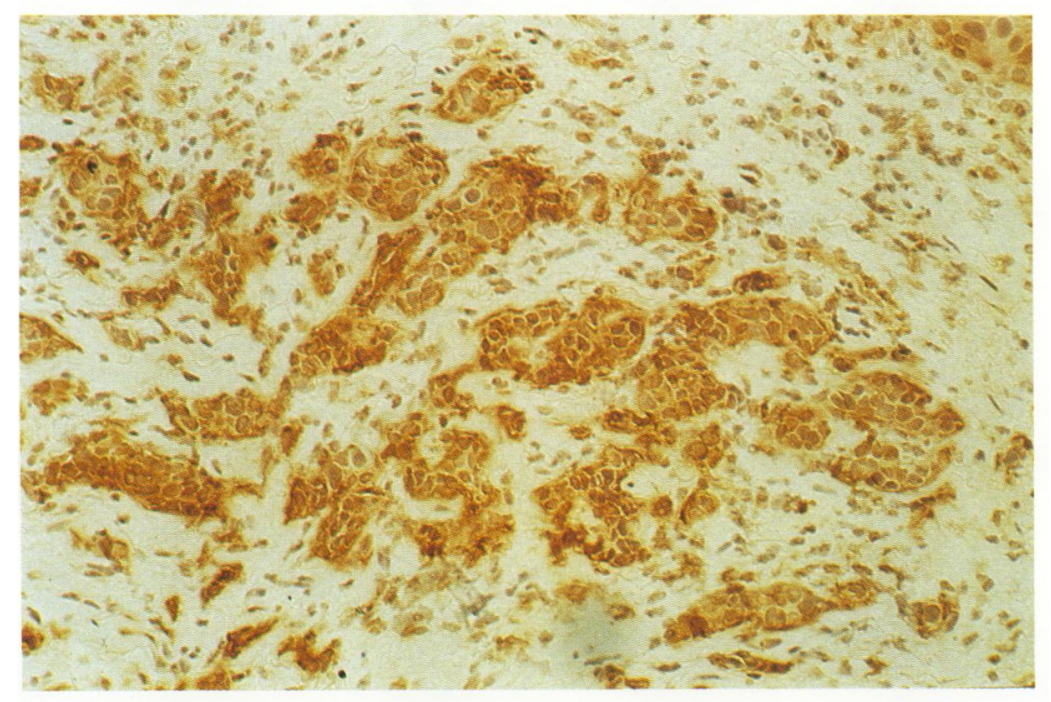

(B)

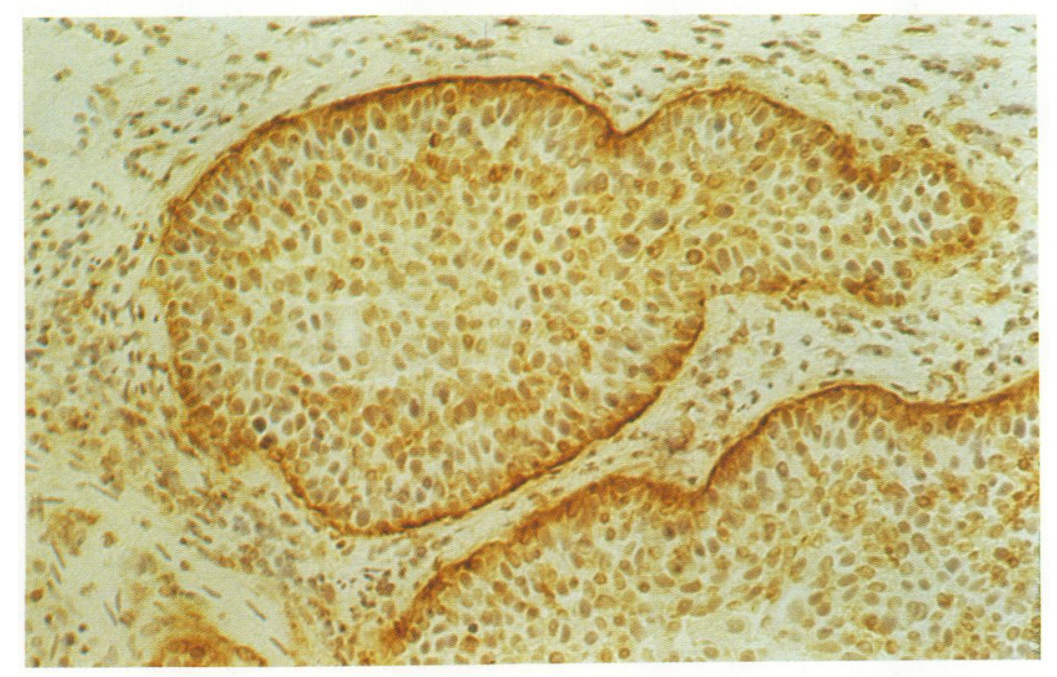

(C)

Figure 5 Positive reactions for Tfr in: (A) Non-invasive papillary TCC grade 2-3.

(B) Grade 3 TCC with muscle invasion. (C) Grade 2-3 TCC with invasion which shows characteristic localisation of the positive staining at the periphery of the tumour islands.

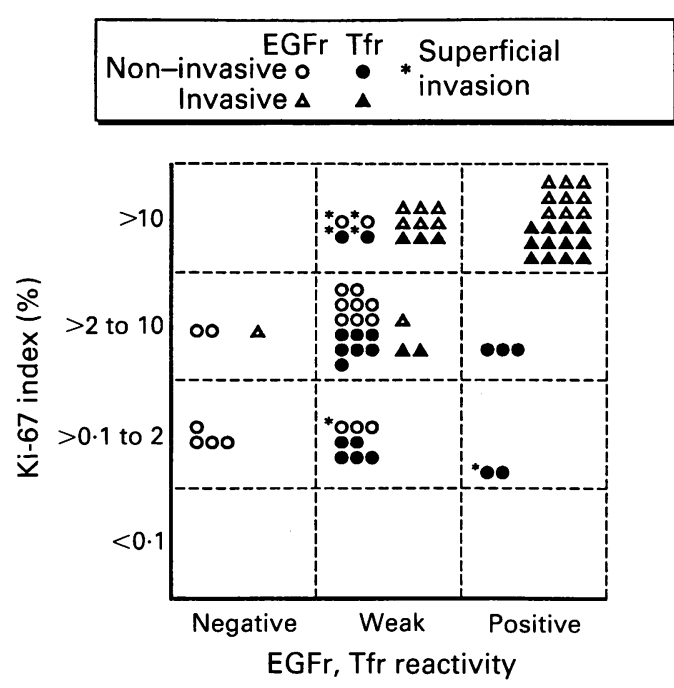

Figure 6 Distribution of TCCs according to the Ki-67 index and the reactivity for EGFr, Tfr.

clinical relevance of the enhanced proliferation and receptor expression in some of these cases.

On the basis of these data, we conclude:

(a) Morphologically normal urothelium has a very low turnover rate and weak reactivity for EGFr and TFr, mostly in the deeper layers. No enhancement is seen in any of the three variables in patients with a history of or coexistent urothelial neoplasia.

(b) The $\mathrm{Ki}-67$ index is considerably increased in carcinomas with muscle invasion and in cases of severe atypia-CIS. Significant, but not as high, increases are also found in noninvasive papillary TCCs and some cases of moderate atypia. The increases in the $\mathrm{Ki}-67$ index are not necessarily accompanied by enhancement of the receptor detectability. In particular, the EGFr falls behind the $\mathrm{Ki}-67$ index so that the level of its expression cannot be used as a measure of proliferative activity. Despite this discrepancy strong reactivity for EGFr is useful in confirming the presence of muscle invasion. The discrepancies between $\mathrm{Ki}-67$ and receptor expression may, in part, be due to technical limitations, but we believe that they also reflect the complex and multifactorial nature of neoplasia.

This work was supported by a grant-in-aid [CA33239] from the National Cancer Institute, National Institutes of Health, Bethesda, Maryland.

1 Neal DE, Bennett MK, Hall RR, et al. Epidermal growth factor receptors in human bladder cancer: Comparison of invasive and superficial tumours. Lancet 1985; i: of invasive

2 Messing EM, Hanson P, Ulrich P, Erturk E. Epidermal growth factor-interactions with normal and malignant urothelium: in vivo and in situ studies. $\mathcal{F}$ Urol 1987; 138: 1329-37.

3 Limas C. Relationship of epidermal growth factor receptor detectability with the A, B, H, blood group antigens: Emphasis on normal and neoplastic urothelium. Am $\mathfrak{f}$ Pathol 1991;139:131-7.

4 Wood DP, Fair WR, Chagati RSK. Evaluation of the epidermal growth factor receptor DNA amplification and mRNA expression in bladder cancer. $\mathcal{f}$ Urol 1992; 147:274-9.

5 Brown DC, Gatter KC. Monoclonal antibody Ki-67: Its use in histopathology. Histopathology 1990;17:489-503.

6 Gerdes $\mathrm{J}, \mathrm{Li} \mathrm{L}$, Schlueter $\mathrm{C}$, et al. Immunobiochemical and molecular biologic characterization of the cell pro- 
liferation associated nuclear antigen that is defined by monoclonal antibody Ki-67. Am $\mathcal{F}$ Pathol 1991;138: 867-73.

7 Carpenter G, Cohen S. Epidermal growth factor. Annu Rev Biochem 1979;48:193-216.

8 Yudd W, Poodry CA, Strominger JL. Novel surface antigen expressed on dividing cells but absent from nondividing cells. 7 Exp Med 1980;152:1430-5

9 Sutherland R, Delia D, Schneider C, et al. Ubiquitous cell surface glycoprotein on tumour cells is prolife surface glycoprotein on tumour cells is proliferationassociated receptor for

10 Gatter KC, Brown G, Trowbridge IS, Woolston RE, Mason DY. Transferrin receptors in human tissues: Mason DY. Transferrin receptors in human tissues: their distribution and

11 Smith NW, Strutton GM, Walsh MD, et al. Transferri receptor expression in primary superficial human bladder tumours identifies patients who develop recurrences. Br $\mathcal{F}$ Urol 1990; 65:339-44. 12 Koss LG. Tumours of the urinary bladder. In: Atlas of
tumour pathology, Fascicle 11. Washington, DC: Armed Forces Institute of Pathology, 1975.

13 Kern WH. Urinary tract. In: Bibbo M, ed. Comprehensive cytopathology. Philadelphia, PA: WB Saunders, 1991: cytopatholog 67.

14 Waterfield MD, Mayes ELV, Stroobaut P, et al. A monoclonal antibody to the human epidermal growth factor recer 7 Cell Biochem 1982:20:149-61.

15 Gerdes J, Schwab U, Lemke H, Stein H. Production of mouse monoclonal antibody reactive with a human nuclear antigen associated with cell proliferation. Int $\mathcal{f}$ Cancer 1982;31:13-20.

16 Dubeau L, Jones PA. Growth of normal and neoplastic urothelium and response to epidermal growth factor in a defined serum-free medium. Cancer Res 1987;47: 2107-12.

17 Sufrin G, Meyer JS, Marin SA, Schechtmau K Proliferative activity of urothelium and tumours of rena pelvis, ureter and urinary bladder evaluated by thymidine labeling. Urology 1984;(Suppl)23:15-22.

18 Limas C, Bigler A, Bair R, Bernhart $P$, Reddy $R$. Proliferative activity of urothelial neoplasms: comparison of BrdU incorporation, $\mathrm{Ki} 67$ expression, and parison of BrdU incorporation, Kin expression, and nucleolar

19 Tsujihashi H, Matsuda H, Uejima S, Akiyama T, Kurita $\mathrm{T}$. Cell proliferation of human bladder tumours. $\mathcal{F}$ Uro 1989;142:1113-16

20 Mulder AH, Van Hootegen JC, Sylvester R, et al. Prognostic factors in bladder carcinoma: Histological parameters and expression of a cell cycle-related nuclear antigen (Ki-67). F Pathol 1992;166:37-43.

21 Mellon K, Neal DE, Robinson MC, Marsh C, Wright C. Cell cycling in bladder carcinoma determined by monoclonal antibody Ki-67. Br f Urol 1990;66:281-5.

22 Koss LG, Nakaniski I, Freed SZ. Non-papillary carcinoma in situ and atypical hyperplasia in cancerous bladders: Further studies of surgically removed bladders by mapping. Urology 1977;9:442-54. 